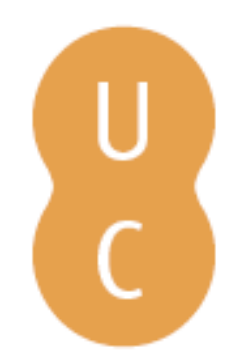

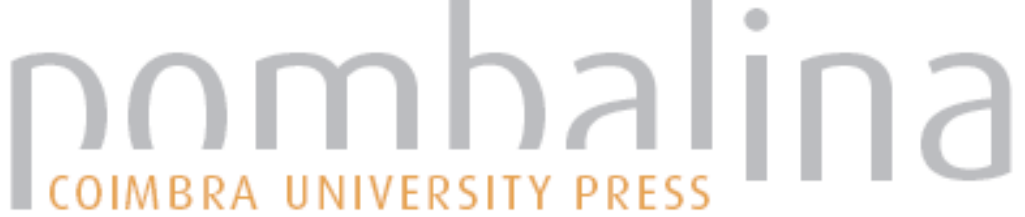

\section{A gloria olímpica numa ode horaciana}

\author{
Autor(es): $\quad$ Couto, Aires Pereira do
}

Publicado por: Imprensa da Universidade de Coimbra

URL

persistente: URI:http://hdl.handle.net/10316.2/38373

DOI: $\quad$ DOI:http://dx.doi.org/10.14195/978-989-26-0371-1_11

Accessed : $\quad$ 26-Apr-2023 01:34:38

A navegação consulta e descarregamento dos títulos inseridos nas Bibliotecas Digitais UC Digitalis, UC Pombalina e UC Impactum, pressupõem a aceitação plena e sem reservas dos Termos e Condições de Uso destas Bibliotecas Digitais, disponíveis em https://digitalis.uc.pt/pt-pt/termos.

Conforme exposto nos referidos Termos e Condições de Uso, o descarregamento de títulos de acesso restrito requer uma licença válida de autorização devendo o utilizador aceder ao(s) documento(s) a partir de um endereço de IP da instituição detentora da supramencionada licença.

Ao utilizador é apenas permitido o descarregamento para uso pessoal, pelo que o emprego do(s) título(s) descarregado(s) para outro fim, designadamente comercial, carece de autorização do respetivo autor ou editor da obra.

Na medida em que todas as obras da UC Digitalis se encontram protegidas pelo Código do Direito de Autor e Direitos Conexos e demais legislação aplicável, toda a cópia, parcial ou total, deste documento, nos casos em que é legalmente admitida, deverá conter ou fazer-se acompanhar por este aviso. 
FRANCISCO DE OLIVEIRA

Coordenação

Ospírito Olímpico

no

novo milénio 


\section{A GLORIA OLÍMPICA NUMA ODE HORACIANA}

Air es Per eir a do Couto

Universidade Católica

A ode que abre o livro primeiro das Odes de Horácio é dedicada a MecenasO, um político romano descendente da nobreza etrusca, que era amigo, colaborador e um dos principais conselheiros de Octávio, o futuro imperador Augusto. Mecenas sobressaiu particularmente pelo apoio que concedeu aos homens das artes e das letras, nascendo à sua volta o chamado Círculo de Mecenas, de que fizeram parte poetas como Virgílio, Vário Rufo, Propércio e o próprio Horácio, que foi apresentado a Mecenas por Virgílio e Vário(2), em 38 a.C., acontecimento que viria a influenciar profundamente o rumo da sua vida, pois Mecenas tornar-se- ia seu protector e amigo.

$\mathrm{Na}$ referida ode, o poeta Venusino enumera nove exemplos de diferentes paixões e ambições humanas que determinam a vida de cada homem numa caminhada incessante pela sua concretização. Assim,

São vários os textos de Horácio dirigidos ou dedicados a Mecenas. É, além da ode I.I, o caso das odes 1.20, 2.12, 2.17, 2.20, 3.8 e 3.29; dos epodos I, 3, 9 e 14; das sátiras I.I e 1.6; e das epistolas I.I, 1.7 e 1.19 .

(2) E o próprio Horácio que o diz na sátira 1.6, a melhor e mais extensa memória da sua própria vida. Afirma o poeta;

Nulla etenim mihi te fors obtulit; optimus olim

Vergilius, post hunc Varius dixere quid essem, (v.54- 55)

Na verdade não foi o acaso que te trouxe ao meu conhecimento;

um dia o excelente Virgílio, e depois dele Vário, disseram- te quem eu era. 
segundo Horácio, alguns homens encontram a felicidade na vitória olímpica:

Sunt quos curriculo puluerem Olympicum

collegisse iuuat metaque feruidis

euitata rotis palmaque nobilis

terrarum dominos euehit ad deos, (v.3-6)

Há homens a quem agrada levantar o pó Olímpico na corrida de carros, e a quem a marca evitada pelas rodas escaldantes e a palma gloriosa elevam até aos deuses, tornando- os senhores da terra.

Outros encontram- na no sucesso político:

Hunc, si mobilium turba Quiritium

certat tergeminis tollere honoribus, (v. 7- 8)

Este fica feliz se a multidão dos Quirites inconstantes procura honrá- lo com a tríplice dignidade.

Outros, na abundância da produção agrícola:

Illum, si proprio condidit horreo

quidquid de Lybicis uerritur areis, (v.9- 10)

Aquele (sente- se feliz) se juntou no seu próprio celeiro todo o grão que é varrido nas eiras da Líbia.

Outros, no prazer dos trabalhos agrícolas:

Gaudentem patrios findere sarculo

agros Attalicis condicionibus

numquam dimoueas, ut trabe Cypria

Myrtoum pauidus nauta secet mare. (v. I 1- 14)

Aquele que se sente feliz em abrir com a enxada os campos paternos, nem oferecendo- Ihe a riqueza de Átalo o convencerias a, marinheiro tímido, sulcar com um lenho cíprio o mar de Mirto.

Outros, no comércio marítimo:

Luctantem Icariis fluctibus Africum mercator metuens otium et oppidi laudat rura sui; mox reficit rates quassas, indocilis pauperiem pati. (v. 15- 18) 
Quando o Africo luta com as ondas Icárias, o mercador, assustado, louva o ócio e os campos da sua cidade; mas logo conserta as embarcações danificadas, incapaz de suportar a pobreza.

Outros sentem- se felizes fruindo os prazeres de uma vida ociosa:

\author{
Est qui nec ueteris pocula Massici \\ nec partem solido demere de die \\ spernit, nunc uiridi membra sub arbuto \\ stratus, nunc ad aquae lene caput sacrae, (v. 19- 22) \\ Há quem não recuse os copos do velho Mássico, \\ nem tirar uma parte ao dia inteiro para se estender \\ quer debaixo de um verde medronheiro quer \\ junto da agradável fonte de água sagrada.
}

A outros agradam as actividades bélicas:

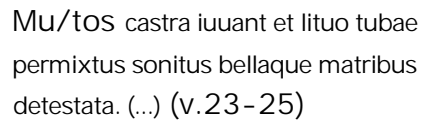

E outros, ainda, sentem prazer na caça:

(...) Manet sub loue frigido

uenator tenerae coniugis inmemor, seu uisa est catulis cerua fidelibus,

seu rupit teretes Marsus aper plagas, (v.25- 28)

(...) Permanece ao relento

o caçador, esquecido da sua jovem esposa, se uma corça foi avistada pelos seus cães fiéis, ou se um javali da região dos Marsos rompeu as redes finas. 
Por fim, Horácio fecha esta enumeração com o seu próprio conceito de felicidade, que ele alcançará através da sua inclusão no número dos poetas líricos:

\author{
Me doctarum hederae praemia frontium \\ dis miscent superis, me gelidum nemus \\ Nympharumque leues cum Satyris chori \\ secernunt populo, si neque tibias \\ Euterpe cohibet nec Polyhymnia \\ Lesboum refugit tendere barbiton. \\ Quod si me lyricis uatibus inseres, \\ sublimi feriam sidera uertice. (v.29- 36)
}

\begin{abstract}
A mim, as heras, prémio das doutas frontes, tornam- me semelhante aos deuses celestes; a mim, o bosque fresco e os coros agradáveis das Ninfas, juntamente com os dos Sátiros, separam- me do povo, se Euterpe não me negar as suas flautas nem Polímnia se recusar a tocar para mim a lira de Lesbos. Se me incluíres entre os poetas líricos, tocarei os astros com a minha cabeça gloriosa.
\end{abstract}

Quando Horácio exprime o desejo de ser incluído no número dos poetas líricos, alude ao cânone de nove poetas líricos gregos, dos quais o primeiro e mais importante era Pindaro, o "regnator lyricae cohortis", como diz Estácio(3), os restantes eram Baquílides, Safo, Anacreonte, Estesícoro, Simónides, Ibico, Alceu e Alcman. $\left({ }^{4}\right)$ Horácio deseja ser poeta lírico, na tradição de Safo e Alceu, e ser o primeiro a introduzir a poesia eólica nos versos latinos. O poeta alcançou estes objectivos: ele próprio o diz na última ode dos seus três primeiros livros, a ode 3.30, na qual faz a sua autoconsagração poética, exprimindo o orgulho de ter conquistado a imortalidade.

Contrapor a vocação lírica a uma enumeração de vários tipos de vida eleitos pelos homens era um procedimento tradicional desde os poetas

(3) Siluae, 4.7.5.

(4) Cf. R. Pfeiffer, History of Classical scholarship, Oxford, 1968, p.205. 
gregos.(5) A diversidade dos prazeres humanos e da sua busca era um velho tópico literário que já aparece em Sólon, fr. 13 West, 43- 58:

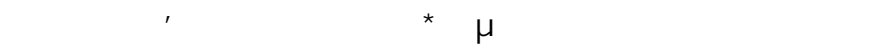

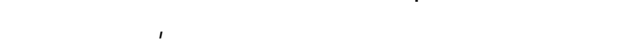

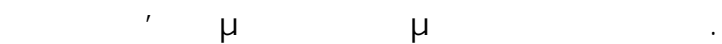

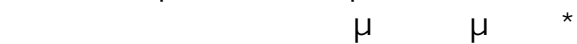

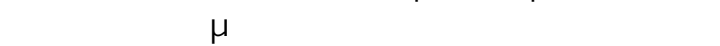

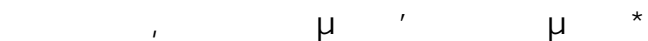

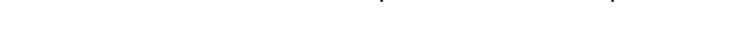

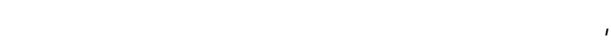

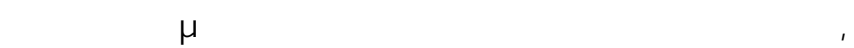

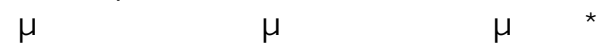

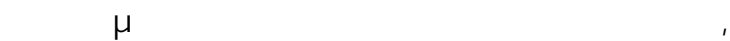

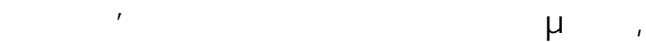

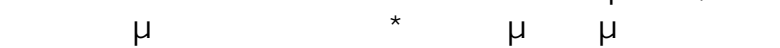

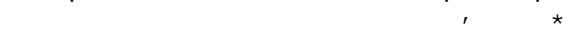

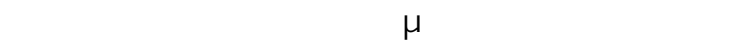

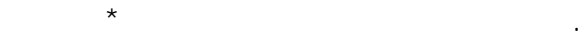

Cada um se afadiga à sua maneira: um vagueia pelos mares piscosos em navios, desejando levar para casa

o lucro, arrastado pelos ventos terríveis, sem pensar em poupar a vida.

Outro, que cuida dos arados recurvos, serve todo o ano, retalhando a terra coberta de árvores.

Outro, instruído nas obras de Atena e do industrioso Hefestos, ganha a vida com suas mãos.

Outro, que aprendeu a ter os dons das Musas Olímpicas, conhece a medida dos encantos da Sabedoria.

A outro, a quem os deuses acompanhavam, Apoio, senhor do arco, fê- lo adivinho; percebe a desgraça

que de longe caminha para o homem; mas o destino marcado, não o evita o arúspice nem os sacrifícios.

Outros são médicos, que exercem o ofício de Péon, rico em remédios; mas não alcançam o fim. ${ }^{(6)}$

(5) Cf. R. G. M. Nisbet and Margaret Hubbard, A Commentory on Horace Odes, Book I, Oxford, Clarendon Press, reimpr. 1989, p.2-3. Aí são citados exemplos de Safo (fr. 16), de Píndaro (Nemeia 8.37 sqq.) e de Eurípides (frag. 659. I sqq.).

${ }^{(6)}$ A tradução aqui apresentada é da Professora M. H. Rocha Pereira (Hélade. Antologia da Cultura Grega, Coimbra, 81995, p. 108- 109). 
Este mesmo tópico está presente em Pindaro, frag. 96 (edição de Puech)(7);

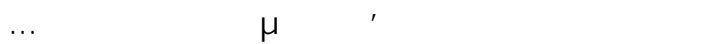

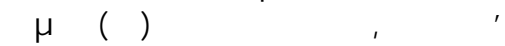

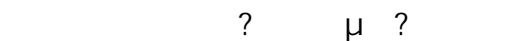

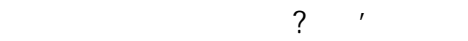

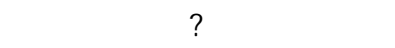

Há aqueles a quem agrada a glória e as coroas dos

cavalos rápidos como a tempestade, a outros agrada

viver em quartos onde abunda o ouro;

outros gostam de atravessar, sãos e salvos,

o turbilhão marítimo num rápido navio.

Este tópico serviu ainda de objecto de especulação para os filósofos gregos, ao compararem a actividade filosófica a outros tipos de tarefas. É o caso de Platão, na República 581c, e de Aristoteles, na Ética a Nicómaco I095bl7sq.(8)

Voltemos agora ao primeiro dos exemplos de paixões humanas apresentados por Horácio - o da vitória olímpica. Este exemplo é um tópico habitual nos "catálogos de ocupações" apresentados por autores gregos, como por exemplo: Pindaro (frag. 96 da edição de Puech), Diógenes Laércio (8.8) ou lâmblico (Vida de Pitágoras 58).(9)

$\mathrm{Na}$ Grécia do século $\mathrm{V}$ a.C., os jogos eram numerosos, mas entre eles sobressaíam quatro: os jogos Píticos, que se realizavam em Delfos, os Istmicos, em Corinto, os Nemeus, em Nemeia, e os mais importantes, os Olímpicos, em Olímpia.

Quando Horácio escreveu esta ode, possivelmente em 23 a.C., pouco tempo antes da publicação dos três primeiros livros das odes - o que aconteceu ainda nesse mesmo ano - os Jogos Olímpicos já tinham perdido muita da sua antiga glória.

O início oficial dos Jogos Olímpicos remonta a 776 a.C., data a partir da qual os nomes dos vencedores das provas começaram a ser anotados em registos públicos. Atingiram o seu auge no século $V$ a.C.. Com o

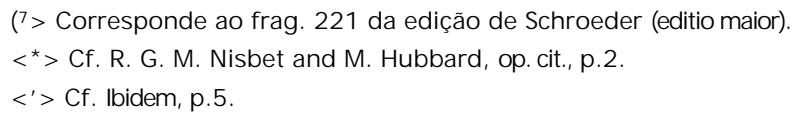


domínio romano da Grécia e da Macedónia, no século II a.C, as competições entraram em contínua decadência, por motivos vários, dos quais se pode realçar o próprio temperamento do povo romano que não via a competição desportiva com o espírito quase religioso dos gregos. Apesar dos esforços de imperadores como Nero, Adriano e Tibério - este último venceu mesmo uma corrida de carros no ano 4 vão desaparecendo do programa olímpico provas como as corridas de carros e multiplicam-se as que se caracterizam pela violência. O desinteresse pelos jogos foi aumentando, até que, em 393, o imperador Teodósio I os proibiu por serem considerados festivais pagãos. $\mathrm{C}^{0}$ )

Ao contrário do que acontecia na Grécia, na época áurea dos Jogos Olímpicos, em que os vencedores eram celebrados em odes triunfais, de que se destacam as Odes Olímpicas de Pindaro, em Roma, na poesia da época de Augusto apenas surgem algumas breves referências às vitórias olímpicas. E, por exemploC), o que acontece com Propércio, 3.9.17-20, que apresenta versos semelhantes aos de Horácio, dizendo:

\footnotetext{
Est quibus Eleae concurrit palma quadrigae, est quibus in celeres gloria nata pedes;

hic satus ad pacem, hic castrensibus utilis armis: naturae sequitur semina quisque suae.
}

Há homens a quem convém a palma da quadriga olímpica, há aqueles para quem a glória nasceu nos seus velozes pés; este foi criado para a paz, este é hábil nas armas castrenses: cada um segue as inclinações da sua natureza.

Horácio, na sua ode, refere- se especificamente à mais nobre das várias competições dos Jogos Olímpicos^2): a corrida de carros de

(10) Sobre a história dos Jogos Olímpicos, vide H. Schóbel, The Ancient Olympie Games, London, 1966; L. Drees, Olympia, Gods, Artists and Athlètes, London, 1968; e M. I. Finley and H. W. Pleket, The Olympie Games: The First Thousand Years, London, 1976.

(M) Poderão encontrar-se outros exemplos em Virgílio, Georgicas 3.49; Estácio, Siluae 5.2.25- 26.

(12) No seu início, os jogos duravam apenas um dia e tinham no seu programa apenas uma prova: a corrida de velocidade no estádio (uma distância de 192,27m). Com o aumento do prestígio dos Jogos Olímpicos, a sua duração e número de provas foram aumentando, até atingirem no seu período áureo, o século $V$ a.C., uma duração de 5 dias, ao longo dos quais se realizavam as seguintes provas: 4 corridas a pé: o estádio $(192,27 \mathrm{~m})$ para homens e para 
cavalos, na qual o condutor procurava contornar a marca colocada em cada extremidade da pista de corridas, passando o mais próximo possível de cada uma delas sem, no entanto, Ihes tocar. A importância do modo como a marca era contornada é realçada por autores gregos como Homero, na llíada 23.334 sqq., Sófocles, na Electra 743 sqq., e Teócrito 24.119 sqq.. Vejamos o que, a este propósito, o velho Nestor diz, na llíada, ao seu filho Antíloco:

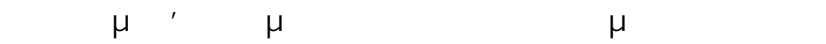

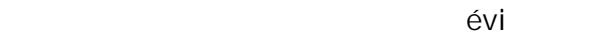

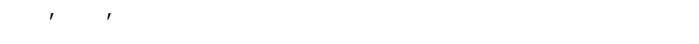

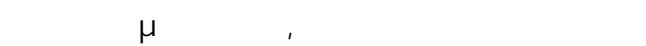

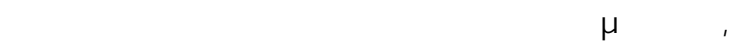

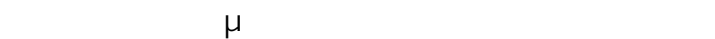

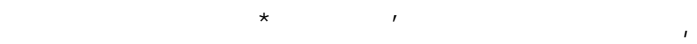

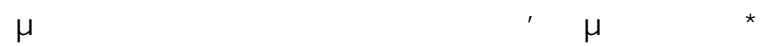

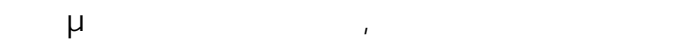

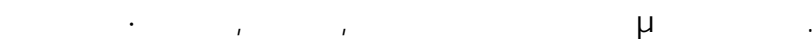

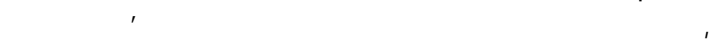

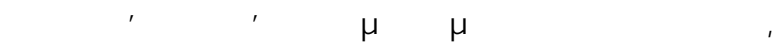

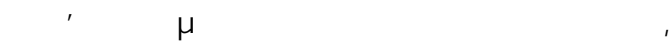

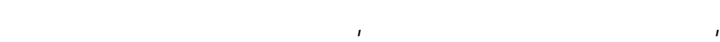

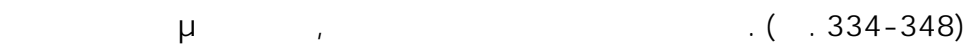

Faz com que o carro e os cavalos passem o mais perto possível da marca, e tu próprio inclina- te ligeiramente para a esquerda no carro bem entrelaçado;

estimula o cavalo da direita com gritos, com o aguilhão, e afrouxando- Ihe as rédeas, mas que o cavalo da esquerda passe tão perto da marca que dê a impressão que o cubo bem feito da roda vai raspar na pedra.

Mas evita, no entanto, tocar- Ihe, para não danificares o carro nem ferires os cavalos, o que traria alegria para os outros e vergonha para ti. Sê, pois, prudente, meu filho, e tem cautela. Se, guiando os cavalos, conseguires passar a marca, não haverá quem te alcance e muito menos te ultrapasse, ainda que te perseguisse o divino Aríone, o rápido cavalo de Adrasto, de origem divina, ou os cavalos de Laomedonte, os melhores que aqui foram criados.

rapazes, o diaulos (duplo estádio), o dolichos (corrida de fundo) e o hoplitodromo (corrida com armas); 3 provas de combate: luta e pugilato para homens e para rapazes, e pancrácio (um misto de luta e pugilato); o pentatlo (corrida, salto, luta, lançamento do disco e do dardo); e duas corridas hípicas: uma em cavalos de sela, outra com carros. 
Voltando à ode do Venusino, é curioso verificar o realce que o poeta dá ao pormenor das rodas dos carros, que ele classifica de rodas escaldantes (feruidis rotis), porque as rodas eram de ferro na sua extremidade e, por isso, ficavam muito quentes durante a corrida, podendo mesmo provocar eventualmente faíscas ao rasparem na marca. Esta mesma ideia aparece em Ovídio, na Arte de amar 3.396:

Metaque feruenti circumeunda rota.

E a marca que deve ser contornada pela roda escaldante.

E em Virgílio, na Eneida I 1.195, onde as rodas também são qualificadas pelo adjectivo feruentes:

Frenaque feruentesque rotas...

Freios e rodas escaldantes...

Horácio termina a referência ao primeiro exemplo de paixão humana aludindo à glória da vitória olímpica, dizendo que "a palma gloriosa" torna os vencedores "senhores da terra"(13) e eleva- os "até aos deuses".

A palma, enquanto símbolo de vitória, não aparece ainda mencionada em Pindaro, pois o prémio começou por ser uma coroa de oliveira brava, uma árvore sagrada que, dizia-se, tinha sido trazida por Hércules do país dos HiperbóreosO4). No entanto, a palma já aparece mencionada como símbolo da vitória no século IV a.C.. Em Roma, é referida pela primeira vez em 293 a.C. 15, como se infere das seguintes palavras de Tito Livio 10. 47. 3:

Palmaeque tum primum translato e Graeco more uictoribus datae.

Então, pela primeira vez, por influência do costume grego, as palmas foram dadas aos vencedores.

(13) Alguns consideram a expressão terrarum dominos como aposto de deos; preferimos, com Kenneth Quinn (Horace. The Odes, Edinburg, Nelson, 1992, p.l) e Nisbet and Hubbard (op. cit., p.6), considerá-lo um aposto de eos, o complemento directo subentendido de euehit, pois parece não haver dúvidas quanto ao sentido que o poeta quer dar à expressão: os vencedores olímpicos sentem- se como verdadeiros senhores da terra.

(14) Cf. Aimé Puech, Pindare. Olympiques, Paris, Les Belles Lettres, 1970 (numa reimp.), p.6; vide também a nota 16.

(IS) Cf. Nisbet and Hubbard, op. cit., p.6. 
A propósito dos prémios dos jogos, Pausanias, no século II depois de Cristo, na sua Descrição da Grécia, 8. 48. 2, diz:

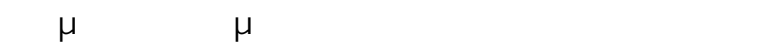

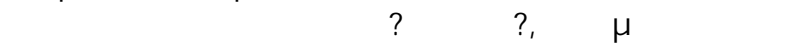

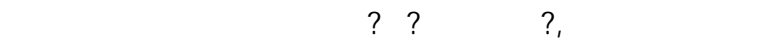

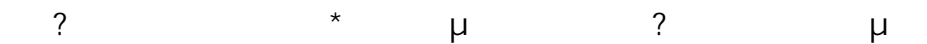

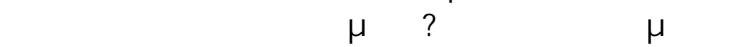

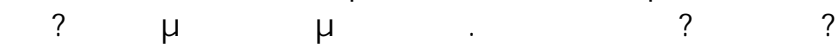

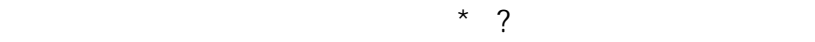

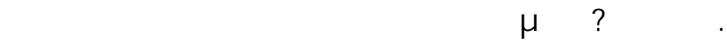

Por que razão em Olímpia se dá uma coroa de oliveira brava ao vencedor, e em Delfos de loureiro, já expliquei a causa da primeira no livro sobre a Elide(16), e da segunda fá- lo- ei depois. No Istmo eram usadas as de pinheiro, e em Nemeia as de aipo, para comemorar os sofrimentos de Palémon e de Arquémoro. Mas a maioria dos jogos concede uma coroa de palma, a qual é colocada, em todos, na mão direita do vencedor.(17)

Interessante é, também, um passo de Heródoto, 8. 26, a propósito dos prémios dos Jogos Olímpicos, no qual o persa Tritantaicmes, filho de Antábano, ao ser informado de que o prémio pelo qual lutavam os Gregos nos Jogos Olímpicos era uma coroa e não dinheiro, não resistiu a exclamar:

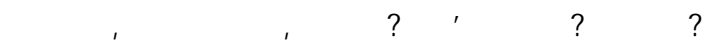

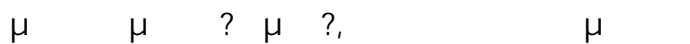

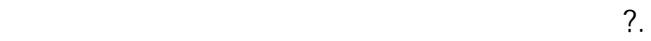

Ai Mardónio, que homens são esses contra quem nos levas a combater, se eles não lutam pela riqueza, mas só pela superioridade ${ }^{(18)}$

Horácio qualifica a palma com o adjectivo nobilis, transferindo para ela a característica habitualmente aplicada ao vencedor.

A glória alcançada pelos vencedores olímpicos faz deles, segundo o poeta, verdadeiros senhores da terra, e fá- los sentirem-se verdadeiros 
deuses. Horácio repete esta ideia na ode 2 do livro quarto, recordando as celebrações que Pindaro faz dos vencedores dos Jogos Olímpicos, cuja glória era, segundo o poeta, "superior à de cem estátuas." Esta afirmação é feita numa ode em que Horácio enaltece o engenho e as virtudes poéticas de Pindaro, quer ele celebre os deuses ou os reis, quer celebre o pugilista ou o cavaleiro que regressa a casa com a palma olímpica que o iguala aos deuses:

Seu deos regesque canit... (v.13)

Siue quos Elea domum reducit palma caelestis pugilemue equomue dicit et centum poti ore signis munere donat, (v. 17- 20)

Embora o prémio pela vitória fosse uma coroa de oliveira ou uma palma e, naturalmente, a glória eterna, como afirma Pindaro na sua la Ode Olímpica:

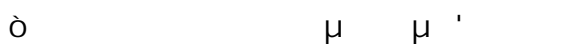

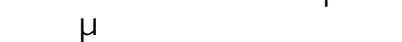

$\alpha \varepsilon^{\prime} \theta \lambda \omega \nu \gamma^{\prime} \varepsilon \nu \varepsilon \kappa \varepsilon \nu$. To $\delta^{\prime} \alpha i ́-$

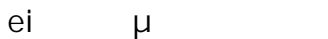

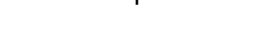

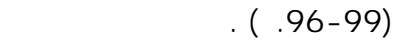

O vencedor goza, para o resto da vida, uma ventura doce como o mel, graças aos prémios.

Um bem que se não perde acompanha os mortais até ao fim. ${ }^{(19)}$

Ou ainda na VIlla Ode Olímpica, onde, a propósito da vitória nos jogos olímpicos, diz:

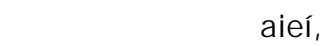

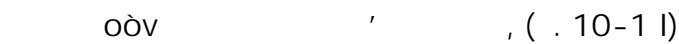

Grande, fulgente é a glória

que sempre acompanha o teu prémio.(20)

(19) Tradução da Professora M. H. Rocha Pereira, ibidem, p. 152.

(20) Tradução da Professora M. H. Rocha Pereira, op. cit., p. 163. 
No entanto, o prémio pela vitória não se limitava à glória eterna, pois, quando regressavam à sua cidade, os atletas vencedores recebiam várias recompensas, algumas delas pecuniárias, e passavam a gozar de vários privilégios que, por exemplo, os isentavam de pagamentos de impostos ou Ihes atribuíam pensões vitalícias, pois a glória olímpica não era sentida como um exclusivo do vencedor, ela estendia-se a toda a sua cidade que a sentia também como sua.

Nos Jogos Olímpicos Modernos, que tiveram no Barão Pierre de Coubertin o seu grande impulsionador e que se iniciaram em Atenas, em 1896, os vencedores já não recebem uma coroa de oliveira ou de palma, mas sim uma medalha, de ouro para o primeiro classificado, de prata para o segundo e de bronze para o terceiro. A glória da vitória olímpica, essa mantém-se inalterada, até na forma como a terra natal do vencedor ou mesmo um país inteiro a sentem como sua. Alguns dos vencedores atingem $\mathrm{o}$ estatuto de verdadeiros heróis, assumem-se como uma verdadeira personificação da glória. Isto mesmo podemos vislumbrar em atletas como por exemplo Jesse Owens, vencedor de 4 medalhas de ouro nos Jogos Olímpicos de Berlim, em 1936, que demonstrou a Hitler, que se recusou a apertar- Ihe a mão, que a raça ariana não era superior à negra; ou Cari Lewis, vencedor de 9 medalhas olímpicas; ou ainda Nadia Comaneci que, nos Jogos Olímpicos de Montreal, em 1976, encantou o mundo com as suas magníficas provas de ginástica e se tornou na primeira ginasta a obter a nota máxima.

Naturalmente, também as recompensas e os privilégios atribuídos aos vencedores dos Jogos Olímpicos Modernos não ficam aquém daqueles que eram atribuídos aos vencedores dos Jogos Olímpicos da Antiguidade, mas a verdade é que, mais importante do que essas recompensas ou privilégios, continua, indubitavelmente, a ser a glória eterna da vitória olímpica. 